\title{
Effect of carrier type on the spray-dried willowherb (Epilobium angustifolium L.) leaves extract, powder properties and bioactive compounds encapsulation
}

\author{
Miloš Jovanović1 ${ }^{*}$, Zorica Drinić ${ }^{1}$, Dubravka Bigović ${ }^{1}$, Gordana Zdunić ${ }^{1}$, Jelena \\ MUdRIĆ $^{1}$, AND KATARINA ŠAVIKIN ${ }^{1}$ \\ ${ }^{1}$ Institute for Medicinal Plants Research "Dr. Josif Pančić”, Tadeuša Košćuška 1, 11000 Belgrade, Serbia \\ *Corresponding author: mjovanovic@mocbilja.rs
}

Published: December 25, 2021

Received: February 7, 2021

Accepted: July 2, 2021

Published on-line: December 1, 2021

\begin{abstract}
Willowherb (Epilobium angustifolium L.) leaves are a valuable source of polyphenolic compounds (phenolic acids, flavonoids, and ellagitannins) that are mainly used in the treatment of benign prostatic hyperplasia. In the presented study, the impacts of maltodextrin and whey protein as carriers on the efficiency of spray drying and physicochemical properties of the obtained powders were examined. The use of carriers significantly improved the drying yield (over $60 \%$ ). Moisture content, hygroscopicity, and rehydration time of all dried extracts (without the carrier, with maltodextrin and whey protein) were at an acceptable level, while their flowability and cohesiveness were poor. The encapsulation efficiency of polyphenols in a whey protein carrier of $92.02 \%$ was significantly higher compared to $75.80 \%$ for maltodextrin. These results show that whey protein efficiently encloses the extract ingredients into powder particles and thus preserves sensitive phenolic compounds during the

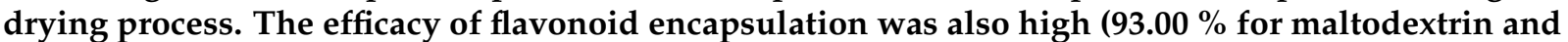
$94.34 \%$ for whey protein), with no statistically significant differences between carrier types. Therefore, willowherb leaves extract can be successfully encapsulated by spray drying using maltodextrin and whey protein as carriers.
\end{abstract}

Key words: Epilobium angustifolium; willowherb; microencapsulation; wall materials; spray dry; phenolics

http://dx.doi.org/10.5937/leksir2141041J

\section{INTRODUCTION}

The genus Epilobium (Onagraceae) encompasses approximately 200 plant species distributed worldwide. Among them, one of the best known medicinal plants is Epilobium angustifolium L. (syn. Chamaenerion angustifolium (L.) Scop.), commonly named willowherb or fireweed (Granica et al., 2014). In folk medicine, teas of willowherb are mostly used in the treatment of urinary tract diseases, such as micturition, benign prostatic hyperplasia, prostatitis, and urethral inflammation. Apart from urinary disease, the willowherb is traditionally used to treat wounds and skin diseases, pain (migraine headaches, childbirth, stomach ache, sore throat), menstrual disorders, gastrointestinal disorders, insomnia, fever (Granica et al., 2014; Schepetkin et al., 2016; Shikov et al., 2006; Sõukand et al., 2020). The justification for its use to reduce nocturia in subjects with benign prostatic hyperplasia was confirmed by clinical trial (Esposito et al., 2021). The main pharmacologically active ingredients of willowherb extracts are polyphenols including phenolic acids, flavonoids and ellagitannins. The dominant secondary metabolite in all Epilobium species and main active principle is the macrocyclic ellagitannin oenothein B (Hevesi Tóth et al., 2009). The dominant flavonoid in E. angustifolium is miquelianin (quercetin-3-O-glucuronide) unlike other Epilobium species where the predominant glycosides are derivatives of kaempferol and myricetin. E. angustifolium is a rich source of phenolic acids such as ellagic acid, chlorogenic acid, benzoic acid, trans-cinnamic acid and their derivatives (Granica et al., 2014; Schepetkin et al., 2016; Stolarczyk et al., 2013).

Instability in an environment of high humidity, light and oxygen, unpleasant astringent taste and low bioavailability of polyphenolic compounds can significantly affect the therapeutic efficacy of extracts. These limitations could be solved using encapsulation techniques such as spray drying (Ćujić Nikolić et al., 2018). By encapsulation, the liquid form of the extract is converted into a powder in which the active ingredients are trapped in the coating of the wall materials (carriers) Encapsulation improves the processing and storage stability as well as release control and targeted drug delivery, enables 
easier handling and masking unpleasant tastes. The obtained powder can be used as a final product (instant tea) or as a semi-finished product for further processing and incorporation into advanced drug formulations (Bakowska-Barczak and Kolodziejczyk, 2011; Ballesteros et al., 2017; Mahdi et al., 2020). Spray drying as a quickly, uncostly, affordable and flexible technique is suitable for large-scale powders production in the pharmaceutical and food industry with acceptable encapsulation efficiency (Chaumun et al., 2020). Choosing the optimal carriers is one of the key steps in the development of the appropriate encapsulation process. The carriers should provide maximum incorporation and retention of the extract ingredients, to create a protection against damaging impact, to be biodegradable, safe and compatible with active compounds Carbohydrate- and protein-based natural biopolymers, including maltodextrin (MD) and whey protein (WP) are the most commonly used carriers for encapsulation via spray drying (Mahdi et al., 2020). To our knowledge, no encapsulation study of E. angustifolium extract by spray drying has been performed. The aim of presented study was to evaluate the encapsulation efficiency of polyphenolic compounds from E. angustifolium leaves using spray drying technique with two different, commonly used, carriers (maltodextrin as carbohydrate carrier and whey protein as protein carrier) and to characterize the encapsulated powders.

\section{MATERIALS AND METHODS}

\subsection{Chemicals}

Maltodextrin (DE16-19.9) was provided from Davisco Foods International (Le Sueur, MN, USA) and whey protein was provided from Polmlek (Raciąż, Poland). Folin-Ciocalteu reagent, gallic acid, catechin, and sodium carbonate were purchased from Sigma-Aldrich Chemie GmbH (Munich, Germany). All other chemicals used in this study were of analytical reagent grade.

\subsection{Plant material and preparation of liquid extract}

Willowherb (Epilobium angustifolium L.) leaves were obtained from the Institute for Medicinal Plants Research "Dr. Josif Pančić". Liquid extract was prepared by decoction with solid to solvent ration 1:20. After extraction, extract was immediately filtered through the filter paper with pore size 4-12 $\mu \mathrm{m}$ (Schleicher \& Schuell, Dassel, Germany). Obtained liquid extract was collected into the glass flask and used for future experiments.

\subsection{Spray drying process}

Liquid willowherb extract (LE) was spray dried with and without carrier addition. Two different biopolymers, MD and WP, in concentrations of $20 \%$ were used. Each biopolymer was separately dissolved in a previously produced LE, and the concentration used in experiments were calculated based on the dry weight of the LE. The prepared solutions were heated at $40{ }^{\circ} \mathrm{C}$ and mixed using magnetic stirrer to completely homogenization, before the spray drying process. The liquid feed was spray dried in a Labtex ESDTi spray dryer (Labtex, Huddersfield, UK) with $0.5 \mathrm{~mm}$ standard diameter nozzle under following conditions: inlet temperature $130 \pm 5^{\circ} \mathrm{C}$, outlet temperature $80 \pm 5^{\circ} \mathrm{C}$, spraying air flow rate $\left(75 \mathrm{~m}^{3} / \mathrm{h}\right)$, liquid feed $(10.8 \mathrm{~mL} / \mathrm{min}$ rate), atomization pressure ( $2.6 \mathrm{bar})$. The obtained spray-dried willowherb extract was separated from the air by a cyclone. Free-flowing powders were obtained and transferred to high-density glass bottles before analyses. They were stored in the dark, in desiccator at room temperature, and these conditions ensured physical stability and active compounds preservation.

\subsection{Powder yield}

The yield (Y) of drying process was calculated as the ratio between mass ( $\mathrm{g}$ ) of the spray-dried extract and the expected mass:

$$
Y[\%]=\frac{m_{\text {extract }}}{m_{\text {expected }}} \times 100
$$

Expected mass was calculated as the sum of share of dry residue in LE multiplied with a mass of LE used for drying process and mass of the used carrier:

$$
m_{\text {expected }}[g]=m_{\text {dry residue }} \times m_{L E}+m_{\text {carrier }}
$$

\subsection{Physical characterization of powders 2.5.1. Moisture content}

The moisture content of each sample was analyzed thermo gravimetrically. The collected powders were dried at $105^{\circ} \mathrm{C}$ until they achieved constant weight using Halogen Moisture Analyzer HB43-S by Mettler Toledo. The results are expressed as a percentage $(\%)$ relative to the dried extract.

\subsubsection{Flowability properties}

For the determination of bulk density, $2 \mathrm{~g}$ of powder was gently loaded into a $10 \mathrm{ml}$ graduated cylinder. The measured volume read directly from the cylinder was used to calculate the bulk density $\left(\rho_{b u l k}\right)$ according to the ratio of mass to volume. In order to determine the tapped density $\left(\rho_{\text {tapped }}\right)$ of extract powders, the cylinder was tapped for 120 times and the volume of the sample was read (Jinapong et al., 2008). Flowability and cohesiveness values of the powders were evaluated in terms of Carr index (Carr, 1965), and Hausner ratio (Hausner, 1967), respectively. Both, CI and HR, were calculated from the bulk $\left(\rho_{\text {bulk }}\right)$, and tapped $\left(\rho_{\text {tapped }}\right)$ densities of the powder by using next equations:

$$
\begin{gathered}
\text { Carrindex }=\frac{\rho_{\text {tapped }}-\rho_{\text {bulk }}}{\rho_{\text {tapped }}} \times 100 \\
\text { Hausner ratio }=\frac{\rho_{\text {tapped }}}{\rho_{\text {bulk }}}
\end{gathered}
$$

\subsubsection{Hygroscopicity}

Hygroscopicity of powders was determined according to the modified method of (Cai and Corke, 2000). Approximately $1 \mathrm{~g}$ of obtained powder was placed at room temperature in stability chamber (Memmert, Schwabach, Germany), filled with $\mathrm{NaCl}$ saturated solution (70 \% RH). Hygroscopicity was monitored during 7 days. Results were expressed in percent $(\%)$, and calculated as gram of absorbed water (moisture) per $100 \mathrm{~g}$ of powders $(\mathrm{g} / 100 \mathrm{~g})$.

\subsubsection{Rehydration}

Rehydration time of powders is a period during the dry extract is completely dissolved in water at room temperature. Tests were carried out on magnetic stirrer, and it has been measured the time taken to fully reconstitute $1 \mathrm{~g}$ of powder in $50 \mathrm{~mL}$ of water, expressed in seconds (s) (Goula and Adamopoulos, 2010).

\subsection{Chemical characterization of powders}

\subsubsection{Total phenolic content}

For TP determination, Folin-Ciocalteu assay with slight modifications was applied (Waterman and Mole, 1994). The reaction mixture was prepared by mixing $200 \mu \mathrm{L}$ of each sample and $1000 \mu \mathrm{L}$ of $10 \%$ Folin-Ciocalteu reagent and after four minutes $800 \mu \mathrm{L}$ of $7.5 \% \mathrm{Na}_{2} \mathrm{CO}_{3}$ was added. The mixture was incubated for 2 hours. Distilled water was used as blank, while control was prepared to contain distilled water instead 
Table 1. Production yield and physical characterization of E. angustifolium powders.

\begin{tabular}{|c|c|c|c|c|c|c|c|}
\hline Extracts & $\begin{array}{r}\text { Powder } \\
\text { yield }^{\mathrm{a}} \\
{[\%]}\end{array}$ & $\begin{array}{r}\text { Moisture } \\
\text { content } \\
{[\%]}\end{array}$ & $\begin{array}{r}\text { Rehydra- } \\
\text { tion } \\
{[\mathrm{s}]}\end{array}$ & $\begin{array}{l}\text { Bulk density } \\
\qquad[\mathrm{mg} / \mathrm{mL}]\end{array}$ & $\begin{array}{r}\text { Tapped } \\
\text { density } \\
{[\mathrm{mg} / \mathrm{mL}]}\end{array}$ & Carr index & $\begin{array}{r}\text { Hausner } \\
\text { ratio }\end{array}$ \\
\hline Without carrier & 47.75 & $4.11 \pm 0.63 \mathrm{a}$ & $20.00 \pm 1.21 \mathrm{a}$ & $131.60 \pm 0.40 \mathrm{c}$ & $227.30 \pm 0.22 \mathrm{~b}$ & $42.11 \pm 0.23 \mathrm{~b}$ & $1.73 \pm 0.01 \mathrm{~b}$ \\
\hline With $20 \% \mathrm{MD}^{\mathrm{b}}$ & 63.76 & $2.43 \pm 0.29 \mathrm{ab}$ & $30.00 \pm 2.00 \mathrm{~b}$ & $116.30 \pm 0.21 \mathrm{a}$ & $185.20 \pm 0.13 \mathrm{a}$ & $37.21 \pm 0.14 \mathrm{a}$ & $1.59 \pm 0.00 \mathrm{a}$ \\
\hline With $20 \% \mathrm{WP}^{\mathrm{c}}$ & 63.18 & $2.04 \pm 0.04 b$ & $30.00 \pm 2.87 \mathrm{~b}$ & $125.00 \pm 0.11 b$ & $227.30 \pm 0.15 b$ & $45.00 \pm 0.20 \mathrm{c}$ & $1.82 \pm 0.01 \mathrm{c}$ \\
\hline
\end{tabular}

${ }^{a}$ Different letters $(\mathrm{a}-\mathrm{c})$ in each column showed a significant difference $(\mathrm{P}<0.05)$ between different extracts according to the post-hoc Tukey test

b MD - stands for maltodextrin

${ }^{c} \mathrm{WP}$ - stands for whey protein

of sample. Absorbance was recorded at $740 \mathrm{~nm}$ after two hours incubation at room temperature. Obtained results were presented as milligrams of gallic acid equivalent per gram of powders (mg GAE/g).

\subsubsection{Total flavonoid content}

The content of total flavonoids (TF) was determined by the aluminum chloride spectrophotometric method described by (Loizzo et al., 2012). The sample absorption was measured at a wavelength of $510 \mathrm{~nm}$. Based on the calibration curve of a standard catechin solution, the content of total flavonoids was determined. The total flavonoid content was expressed as $\mathrm{mg}$ of catechin equivalent per $\mathrm{g}$ dry extract (mg CE/g). All experiments were replicated three times and results were expressed as mean values.

\subsubsection{Encapsulation efficiency}

The encapsulation efficiency (EE \%) for microencapsulated powders were calculated according to the equation:

$$
E E[\%]=\frac{E}{E_{\text {total }}} \times 100
$$

where $E$ represents quantity of TP or TF microencapsulated in the powders, and $E_{\text {total }}$ presents quantity of TP or TF and their respective amount in the LE.

\subsection{Statistical analysis}

All experiments were executed in triplicates determinations. Results were presented as mean value \pm standard deviation. One-way ANOVA was conducted to test the individual factors influence on observed property and Tukey post hoc test was used for differences between the mean values detection. Significant levels were considered at $\mathrm{P}<0.05$ (STATISTICA v.7.0.3). Statistical analysis was performed using the MS Office Excel v. 2010

\section{RESULTS}

\subsection{Production yield}

Powder yield was defined as the ratio of the experimentally obtained powder and the gravimetrically calculated dry residue of the liquid extract. From an industrial point of view, maximizing production yield is one of the essential criteria when choosing a drying aid, as it is closely related to production costs and efficiency. A spray drying process is considered to be of acceptable efficiency if the production yield is greater than $50 \%$ (Vidović et al., 2014). In our study, significant adhesion of particles to the walls of the drying chamber was observed during the drying process of the extract without carrier. Measured yield of $47.75 \%$ for E. angustifolium dry extract without carrier was slightly lower than the mentioned limit, while the yields of powders with MD and WP (63.76 and
$63.18 \%$, respectively) were significantly higher. Obviously, an improvement in the production yield was achieved by the addition of carriers. The reduction of the stickiness of the particles for the chamber walls and the consequent increase of the yield by adding the carriers is in accordance with the results of (Vidović et al., 2014).

The main mechanism of powder yield improvement using carbohydrate carriers such as MD is to increase the glass transition temperature of the feed mixture, thus reducing the particle stickiness. On the other hand, WP does not affect the glass transition temperature but affects the properties of film formation. Actually, WP as a surfactant can migrate to the droplet surface and accelerate the formation of a glassy film in a heated air stream that prevents particles from interacting with the chamber wall (Tontul and Topuz, 2017).



Fig. 1. Hygroscopicity of spray-dried E. angustifolium leaves extract.

\subsection{Physical properties of $E$. angustifolium powders}

The mean values of the examined physical properties for the obtained powders are shown in Table 1 . The residual moisture content of 2.43 and $2.04 \%$ in powders with MD and WP, respectively, was significantly lower compared to $4.11 \%$ in powder without carrier. This is in line with the literature data showing that the moisture content of the spray-dried powder decreases with increasing proportion of the carrier materials in the feed mixture. Low residual moisture in the powder is closely related to the improvement of microbiological stability 
Table 2. Content and encapsulation efficiency of total phenolics and total flavonoids in E. angustifolium extracts.

\begin{tabular}{|c|c|c|c|c|}
\hline \multirow[b]{3}{*}{ Extracts } & \multicolumn{2}{|c|}{ Total phenolics } & \multicolumn{2}{|c|}{ Total flavonoids } \\
\hline & Content $^{\mathrm{a}}$ & $\begin{array}{r}\text { Encapsulation } \\
\text { efficiency }\end{array}$ & Content & $\begin{array}{r}\text { Encapsulation } \\
\text { efficiency }\end{array}$ \\
\hline & {$[\mathrm{mg}$ GAE/g] } & {$[\%]$} & {$[\mathrm{mg} \mathrm{CE} / \mathrm{g}]$} & {$[\%]$} \\
\hline Liquid extract & $448.7 \pm 9.78 \mathrm{c}$ & - & $131.2 \pm 0.85 b$ & - \\
\hline Extracts without carrier & $342.6 \pm 1.65 \mathrm{a}$ & - & $130.7 \pm 0.50 \mathrm{~b}$ & - \\
\hline Extracts with $20 \% \mathrm{MD}^{\mathrm{b}}$ & $340.1 \pm 1.79 \mathrm{a}$ & $75.80 \pm 0.40 \mathrm{a}$ & $122.0 \pm 1.10 \mathrm{a}$ & $93.00 \pm 0.82 \mathrm{a}$ \\
\hline Extracts with $20 \%$ WPc & $412.9 \pm 0.75 b$ & $92.02 \pm 0.17 b$ & $123.8 \pm 1.25 \mathrm{a}$ & $94.34 \pm 0.96 \mathrm{a}$ \\
\hline
\end{tabular}

and the consequent prolongation of the extract shelf-life. If the moisture content is less than $5 \%$, the powder can be classified as microbiologically stable. Apart of microbiological stability, the moisture affects the rheological properties of the powder Namely, moisture acts as a plasticizer due to the depression of the glass transition temperature and affects the caking properties during storage (Tontul and Topuz, 2017; Vidović et al., 2014).

The hygroscopicity of the powders was measured for a week under conditions of high relative humidity. As expected, the largest increase in absorbed moisture in all examined powders was recorded after the first 24 hours with a slight gradual increase in the following period (Figure 1). On the seventh day, hygroscopicity of 3.8, 5.15 and $6.23 \%$ was recorded for powders without carriers, with MD and WP, respectively. Since the observed hygroscopicity of the powders were significantly lower than $20 \%$, they can be considered as poor hygroscopic (Tontul and Topuz, 2017). Interestingly, an inverse relationship between the powder moisture content and its hygroscopicity was observed. The highest hygroscopicity of WP powder can be explained by the high water-holding capacity of the amorphous protein carriers (Tontul and Topuz, 2017).

Instant powder rehydration without lumps and sediments formation is an important benchmark of quality for the end-users. The main strategy for improving the rehydration powder properties is using the spray drying method. The relatively short rehydration time of $20 \mathrm{~s}$ for powder without carrier and $30 \mathrm{~s}$ for powders with MD and WP is satisfactory. Slightly longer rehydration times of extracts with carrier may be associated with additional time required to disassemble the formed crosslinks between biopolymer molecules (Hogekamp and Schubert, 2003).

Assessment the bulk and tapped (compacted) density is relevant for powders used to formulate limiting volume dosage forms, such as tablets or capsules. The highest value of bulk density was recorded in powder without carrier (131.6 $\mathrm{mg} / \mathrm{mL})$, followed by powder with WP $(125.0 \mathrm{mg} / \mathrm{mL})$ and MD (116.3 mg/mL). A similar trend, the highest bulk density for carrier-free Hibiscus sabdariffa extract and slightly lower for extracts with WP and MD was reported by (Díaz-Bandera et al., 2015). The flowability and cohesiveness of the obtained powders were estimated using Carr index and Hausner ratio, which were calculated via bulk and tapped densities. Carr index values of all powders belonging to the range from 35 to 45 indicate bad flowability, possibly due to its stickiness. Also, Hausner ratio values greater than 1.4 for all powders showed their high cohesiveness. Both the Carr index and the Hausner ratio decreased with the addition of $\mathrm{MD}$, indicating that the addition of maltodextrin improved flow properties. The effect of higher concentrations of maltodextrin on flowability prop- erties should be investigated in future studies. The highest Carr index and Hausner ratio recorded in the case of the dried extract with WP can be attributed to the highest hygroscopicity of this powder. Namely, the binding of ambient water increases the cohesiveness between the powder particles and consequently decreases the powder flowability (Caliskan and Dirim, 2016).

\subsection{Encapsulation efficiency}

Encapsulation efficacy was defined as the ratio of the total phenolic/flavonoid content of the experimentally obtained dry extracts and their total content in the liquid extract, expressed in percentage. Results of total phenolic content, total flavonoid content and their encapsulation efficiency in E. angustifolium extracts are presented in Table 2 . The content of total phenolic was highest in the dry extract with $20 \% \mathrm{WP}$ as a drying agent (412.9 mg GAE/g). The content of total polyphenolics in the dry extract with the addition of $20 \%$ MD (340.1 mg GAE/g) was slightly lower compared to the dry extract without carriers (342.6 mg GAE/g). The superior encapsulation efficiency of WP $(92.02 \%)$ compared to MD $(75.80 \%)$ can be partly explained by the possibility of complexation between phenolic compounds and WP molecules (de Morais et al., 2020). These results show that WP carrier effectively encloses the extract ingredients into powder particles and thus preserves sensitive phenolic compounds.

The contents of total flavonoids in dry extracts with the addition of $20 \%$ MD and WP (122.0 and $123.8 \mathrm{mg} \mathrm{CE} / \mathrm{g}$, respectively) were slightly lower compared to the dry extract without carriers (130.7 mg CE/g), probably due to the dilution effect. There were no statistically significant differences between WP $(94.34 \%)$ and MD (93.00\%) as carriers in the encapsulation efficiency of flavonoid compounds.

\section{CONCLUSION}

Willowherb (Epilobium angustifolium) leaves extract was successfully encapsulated by spray drying employing maltodextrin and whey protein as carrier agents. Both carriers significantly improved the drying yield. Dry extracts are characterized by high encapsulation efficiency of polyphenols (over 75 $\%$ ) and flavonoids (over $90 \%$ ), with the superiority of whey protein carrier in this respect. Moisture content below $5 \%$, as well as hygroscopicity that was significantly lower than $20 \%$ for all obtained powders, promise desired extracts stability. The short rehydration time in an aqueous medium (about 20 $\mathrm{s}$ for carrier-free extract and $30 \mathrm{~s}$ for both extracts with carriers), without lumps and sediments, indicates that the obtained dry extracts are acceptable as instant teas. The poor flowability and cohesiveness of the carrier-free extract were slightly 
improved only by maltodextrin. Therefore, spray drying of willowherb leaves extract with maltodextrin and whey protein as carriers can be successfully carried out, providing the preservation of phenolic ingredients.

\section{FUNDING}

This work was supported by the Ministry of Education, Science and Technological Development of the Republic of Serbia, grant number 451-03-68/2020-14/200003.

\section{REFERENCES}

Bakowska-Barczak, A. M. and Kolodziejczyk, P. P. (2011). Black currant polyphenols: Their storage stability and microencapsulation, Industrial Crops and Products 34(2): 1301-1309.

Ballesteros, L. F., Ramirez, M. J., Orrego, C. E., Teixeira, J. A. and Mus satto, S. I. (2017). Encapsulation of antioxidant phenolic compounds extracted from spent coffee grounds by freeze-drying and spray-drying using different coating materials, Food Chemistry 237: 623-631.

Cai, Y. and Corke, H. (2000). Production and Properties of Spraydried Amaranthus Betacyanin Pigments, Journal of Food Science 65(7): 1248-1252.

Caliskan, G. and Dirim, S. N. (2016). The effect of different drying processes and the amounts of maltodextrin addition on the powder properties of sumac extract powders, Powder Technology 287: 308-314.

Chaumun, M., Goëlo, V., Ribeiro, A. M., Rocha, F. and Estevinho, B. N. (2020). In vitro evaluation of microparticles with Laurus nobilis L. extract prepared by spray-drying for application in food and pharmaceutical products, Food and Bioproducts Processing 122: 124-135.

Díaz-Bandera, D., Villanueva-Carvajal, A., Dublán-García, O., QuinteroSalazar, B. and Dominguez-Lopez, A. (2015). Assessing release kinetics and dissolution of spray-dried Roselle (Hibiscus sabdariffa L.) extract encapsulated with different carrier agents, LWT - Food Science and Technology 64(2): 693-698.

de Morais, F. P., Pessato, T. B., Rodrigues, E., Peixoto Mallmann, L., Mariutti, L. R. and Netto, F. M. (2020). Whey protein and phenolic compound complexation: Effects on antioxidant capacity before and after in vitro digestion, Food Research International 133: 109104.

Esposito, C., Santarcangelo, C., Masselli, R., Buonomo, G., Nicotra, G., Insolia, V., D’Avino, M., Caruso, G., Buonomo, A. R., Sacchi, R., Sommella, E., Campiglia, P., Tenore, G. C. and Daglia, M. (2021). Epilobium angustifolium $L$. extract with high content in oenothein $B$ on benign prostatic hyperplasia: A monocentric, randomized, doubleblind, placebo-controlled clinical trial, Biomedicine \& Pharmacotherapy 138: 111414.

Goula, A. M. and Adamopoulos, K. G. (2010). A new technique for spray drying orange juice concentrate, Innovative Food Science \& Emerging Technologies 11(2): 342-351.

Granica, S., Piwowarski, J. P., Czerwińska, M. E. and Kiss, A. K. (2014). Phytochemistry, pharmacology and traditional uses of different Epilobium species (Onagraceae): A review, Journal of Ethnopharmacology 156: 316-346.

Hausner, H. H. (1967). Friction conditions in a mass of metal powder., Int. J. Powder Met., 3: No. 4, 7-13(Oct. 1967). . Institution: Polytechnic Inst. of Brooklyn. Univ. of California, Los Angeles.

Hevesi Tóth, B., Blazics, B. and Kéry, g. (2009). Polyphenol composition and antioxidant capacity of Epilobium species, Journal of Pharmaceutical and Biomedical Analysis 49(1): 26-31.

Hogekamp, S. and Schubert, H. (2003). Rehydration of Food Powders, Food Science and Technology International 9(3): 223-235.

Jinapong, N., Suphantharika, M. and Jamnong, P. (2008). Production of instant soymilk powders by ultrafiltration, spray drying and fluidized bed agglomeration, Journal of Food Engineering 84(2): 194-205.

Loizzo, M. R., Tundis, R., Bonesi, M., Menichini, F., Mastellone, V., Avallone, L. and Menichini, F. (2012). Radical scavenging, antioxidant and metal chelating activities of Annona cherimola Mill. (cherimoya) peel and pulp in relation to their total phenolic and total flavonoid contents, Journal of Food Composition and Analysis 25(2): 179-184.

Mahdi, A. A., Mohammed, J. K., Al-Ansi, W., Ghaleb, A. D., Al-Maqtari, Q. A., Ma, M., Ahmed, M. I. and Wang, H. (2020). Microencapsulation of fingered citron extract with gum arabic, modified starch, whey protein, and maltodextrin using spray drying, International Journal of Biological Macromolecules 152: 1125-1134.
Schepetkin, I. A., Ramstead, A. G., Kirpotina, L. N., Voyich, J. M., Jutila, M. A. and Quinn, M. T. (2016). Therapeutic Potential of Polyphenols from Epilobium Angustifolium (Fireweed): Polyphenols from Fireweed, Phytotherapy Research 30(8): 1287-1297.

Shikov, A. N., Poltanov, E. A., Dorman, H. J. D., Makarov, V. G., Tikhonov, V. P. and Hiltunen, R. (2006). Chemical Composition and in Vitro Antioxidant Evaluation of Commercial Water-Soluble Willow Herb ( Epilobium angustifolium L.) Extracts, Journal of Agricultural and Food Chemistry 54(10): 3617-3624.

Stolarczyk, M., Piwowarski, J. P., Granica, S., Stefańska, J., Naruszewicz, M. and Kiss, A. K. (2013). Extracts from Epilobium sp. Herbs, Their Components and Gut Microbiota Metabolites of Epilobium Ellagitannins, Urolithins, Inhibit Hormone-Dependent Prostate Cancer Cells(LNCaP) Proliferation and PSA Secretion: EFFECT OF EPILOBIUM ON PROSTATE CELLS PROLIFERATION AND PSA SECRETION, Phytotherapy Research 27(12): 1842-1848.

Sõukand, R., Mattalia, G., Kolosova, V., Stryamets, N., Prakofjewa, J., Belichenko, O., Kuznetsova, N., Minuzzi, S., Keedus, L., Prūse, B., Simanova, A., Ippolitova, A. and Kalle, R. (2020). Inventing a herbal tradition: The complex roots of the current popularity of Epilobium angustifolium in Eastern Europe, Journal of Ethnopharmacology 247: 112254

Tontul, I. and Topuz, A. (2017). Spray-drying of fruit and vegetable juices: Effect of drying conditions on the product yield and physical properties, Trends in Food Science \& Technology 63: 91-102.

Ćujić Nikolić, N., Stanisavljević, N., Šavikin, K., Kalušević, A., Nedović, V., Bigović, D. and Janković, T. (2018). Application of gum Arabic in the production of spray-dried chokeberry polyphenols, microparticles characterisation and in vitro digestion method, Lekovite sirovine (38): 916.

Vidović, S. S., Vladić, J. Z., Vaštag, u. G., Zeković, Z. P. and Popović, L. M. (2014). Maltodextrin as a carrier of health benefit compounds in Satureja montana dry powder extract obtained by spray drying technique, Powder Technology 258: 209-215.

Waterman, P. G. and Mole, S. (1994). Analysis of phenolic plant metabolites, Blackwell Scientific, Oxford; Boston. OCLC: 30073068. 